\title{
Seletividade e migração
}

Marden Barbosa de Campos*

\section{Resumo}

A seletividade é uma característica marcante das migrações, dado que os migrantes não são elementos aleatórios em uma população, mas sim indivíduos com características bem definidas. Este trabalho busca aprofundar o debate em torno da seletividade da migração explorando os pressupostos teóricos existentes em diversas abordagens, especialmente os alusivos às causas e aos estímulos dos movimentos migratórios. Será dado destaque especial ao tratamento dado por cada abordagem na maneira como a seletividade expressa-se em relação às características demográficas dos migrantes. Com base na discussão apresentada vê-se que a seletividade é uma característica fundamental do fenômeno migratório, independente da escala de análise e da abordagem conceitual utilizada.

Palavras-chave: Migração, seletividade, características individuais

\footnotetext{
* Analista Socioeconômico da Coordenação de População e Indicadores Sociais do IBGE e Professor da pósgraduação da Escola Nacional de Ciências Estatísticas. Doutor em Demografia pelo CEDEPLAR/UFMG.
} 


\section{Introdução}

A seletividade é uma característica marcante das migrações, dado que os migrantes não são elementos aleatórios em uma população, mas sim indivíduos com características bem definidas. Devido a isto, o conceito de seletividade permeia os pressupostos de várias teorias desenvolvidas para explicar as migrações.

São comuns frases como "dado que a migração é seletiva" ou "natureza seletiva da migração". Bilsborrow (1984), tratando da construção de amostras em pesquisas populacionais, destaca que o migrante é um elemento raro na população, reforçando sua natureza seletiva. Segundo o autor, normalmente apenas uma pequena proporção da população das regiões de origem participa das migrações.

As principais variáveis pelas quais a seletividade migratória expressa-se são a idade e o sexo. Tanto as abordagens teóricas quanto em trabalhos empíricos encontramos forte associação entre idade e migração (ROGER E CASTR0, 1981; BORJAS, 1996; DE JONG e GARDNER, 1981; HEATON, CLIFFORD e FUGUITT, 1981; RADCLIFFE 1992; BURES, 1987; KALLAN, 1993; GOLGHER, 2001; MARQUES e RODRIGUES, 2006). Em relação ao sexo, observa-se que os estímulos à migração de homens $\mathrm{e}$ mulheres são substancialmente diferentes, devido às relações de gênero, que afetam praticamente todos os aspectos do processo migratório (RILEY e GARDNER, 1993; MASON, 1995). Além disto, aspectos como escolaridade, renda, situação ocupacional, condições de saúde e localização espacial são comumente destacados como aspectos importantes na seleção de indivíduos como migrantes.

Cabe ressaltar que políticas migratórias direcionadas podem intensificar a ação da seletividade. Contudo, ainda nos casos de recrutamento e seleção intensional de migrantes, podemos encontrar ainda a seletividade em um nível maior de profundidade. No limite, ela estaria ausente apenas nos casos extremos dos deslocamentos forçados e dos traslados de populações inteiras.

Este trabalho, de cunho teórico, busca aprofundar o debate em torno da seletividade da migração. Serão explorados os pressupostos teóricos existentes em diversas abordagens teóricas, especialmente os alusivos às causas e aos estímulos dos movimentos migratórios. Será dado destaque especial ao tratamento dado por cada abordagem da maneira como a seletividade expressa-se em relação às características demográficas dos migrantes. 


\section{Seletividade e as componentes demográficas}

Pode-se definir "seletividade" como um conjunto de escolhas e preferências que se manifestam em relação a uma situação específica. Assim, seria uma restrição que se faz a algo ou a alguém em detrimento do outro, num processo de diferenciação.

$\mathrm{Na}$ demografia, a seletividade relaciona-se com a ocorrência de um evento demográfico em indivíduos com características específicas dentro de uma população. Sua expressão se manifesta quando estes eventos, como o nascimento, a morte, 0 casamento ou a migração, ocorrem em indivíduos selecionados en tre os demais.

As componentes demográficas mortalidade, fecundidade e migração são seletivas tanto em relação a atributos estritamente individuais, de caráter biológico, como a aspectos culturais, sociais e econômicos (PRESTON, HEUVELINE e GUILLOT, 2001). Além disto, pela natureza própria de cada componente, a seletividade se expressa de maneira diferenciada. Enquanto a seletividade da mortalidade e a da fecundidade têm forte conotação fisiológica, ainda que atrelada aos contextos culturais e às condições sociais, a seletividade migratória é basicamente determinada por questões socioeconômicas. Davis (1989) chega a afirmar que, ao contrário da fecundidade e da mortalidade, a migração praticamente não sofre qualquer constrangimento biológico. Embora, como veremos mais adiante, a ocorrência de migração também esteja relacionada com a idade, 0 que 0 autor enfatiza é 0 fato dela ser prioritariamente uma expressão social, não condicionada por fenômenos biológicos. Ao invés de um atributo fisiológico, a migração pode ser vista como um reflexo ou manifestação de processos e transformações socioeconômicas a ela subjacentes (MOURA, 1980).

Tratando da seletividade dos componentes demográficos, o manual de demografia de Preston, Heuveline e Guillot expõe:

In nearly every population, the rate of occurrence of demographic events varies very sharply with age. (...) In the case of mortality and fertility, this variation mainly reflects age differences in physiological capacity. Age variation in migration rates seems to reflect primarily age differences in economic and social gains from movement. (PRESTON, HEUVELINE e GUILLOT, 2001, p. 21).

\section{Seletividade e teorias migratórias}

Essa seção apresenta o modo como a seletividade da migração em relação aos atributos individuais é tratada pelas principais abordagens teóricas desenvolvidas para a análise migrações. Devemos ressaltar que as teorias apresentadas focam 
especificamente na migração, entendida como a mudança permanente de residência entre duas unidades territoriais estabelecidas.

Ravenstein, no Século XIX, e Lee, no Século passado, podem ser considerados autores "clássicos" no estudo sistemático das migrações (RAVENSTEIN, 1889; LEE, 1966). Embora não sejam os únicos de seu tempo a estudarem o tema, foram autores que abordaram de maneira direta a seletividade das migrações.

Ravenstein buscou elucidar o sentido das migrações com base em "leis que pareciam governá-las", destacou explicitamente o caráter seletivo da migração. Em seu trabalho, a questão econômica foi tida como o principal motivo para a ocorrência da migração, traduzida na "busca de trabalhos mais remuneradores e atraentes" (RAVENSTEIN, 1980, p. 431'). 0 destaque dado à seletividade aparece principalmente em relação ao sexo. Por exemplo, com base em dados dos Recenseamentos Gerais do Reino Unido de 1871 e 1881, 0 autor verificou que as mulheres migravam mais do que os homens em curtas distâncias, embora houvesse preponderância de homens entre os migrantes de longa distância. Essas observações levaram-no a propor como "lei" o fato de que as mulheres migram mais do que os homens.

Em outro trabalho, Everest Lee propôs, em 1966, um modelo de análise das migrações denominado "modelo push-pull", em que aprofunda os conceitos e tipologias definidos por Ravenstein. Neste modelo, a migração ocorre devido a fatores de expulsão e de atração presentes nos locais de origem, de destino e sofre impacto de obstáculos intervenientes. 0 autor pondera que alguns desses fatores afetam pessoas distintas de maneira distinta. Surge daí a afirmação de que as migrações são seletivas.

As migrações são seletivas em razão das pessoas responderem de forma diferente à série de fatores positivos e negativos prevalecentes nos locais de origem e de destino, terem capacidades diferentes para superar as séries de obstáculos e diferenciam-se entre si em termos dos fatores pessoais. (LEE, 1980, p. 111)

Lee dá muita ênfase à questão da seletividade migratória, chegando a afirmar que dado que os migrantes não constituem uma amostra aleatória da população, mas sim indivíduos com características pessoais específicas que respondem de maneira diferente a estímulos e obstáculos, "seria impossivel, portanto, que as migrações deixassem de ser seletivas.” (LEE, 1980, p. 111).

\footnotetext{
${ }^{1}$ As versões utilizadas dos textos de LEE e RAVENSTEIN foram extraídas da tradução do original feita por Helio Moura em MOURA, H. A. (org.). Migração interna, textos selecionados: teorias e métodos de análise. Fortaleza: BNB, 1980.
} 
Ao definir "fatores pessoais" que determinam o processo de seleção de migrantes, Lee descreve aspectos como sensibilidade pessoal, inteligência, nível de conhecimento, informação, contatos pessoais e personalidade. A "força" que os estímulos e obstáculos exercem sobre os indivíduos irá depender, em grande medida, do momento da vida que está sendo vivenciado pelo indivíduo, ou seja, da "etapa do ciclo vital" (LEE, 1980, p. 102). As migrações são tratadas por ele como "rites de passages".

As crianças estão ligadas à residência familiar pela necessidade de cuidado e de subsistência, embora, à medida que se tornam maiores, alcancem idades nas quais é costume cessar uma etapa de desenvolvimento para que tenha início uma outra. Tais ocasiões são a descontinuidade na educação, 0 ingresso no contingente economicamente ativo, ou a aposentadoria. 0 matrimônio também representa mudança semelhante no ciclo vital, como também sua dissolução, seja por divórcio, seja pela morte do cônjuge. (LEE, 1980, p. 103).

Independente da validade e da aplicabilidade das ideias de Ravenstein e Lee, seus estudos ainda hoje são muito importantes como ponto de partida para 0 estudo das migrações, além de serem os primeiros a destacar a questão da seletividade em relação a atributos individuais dos migrantes.

\section{Abordagens econômicas das migrações}

Serão tratados nesta seção os estudos que privilegiam os fatores econômicos como estímulos das migrações. Primeiramente serão tratados os estudos de caráter macroeconômico, que explicam a ocorrência de migração por fatores estruturais como a diferença na oferta e demanda por emprego entre regiões ou as alterações no sistema econômico em que as sociedades estão inseridas. Em seguida, serão apresentados os trabalhos microeconômicos, que tratam das atitudes dos indivíduos ligadas à busca, em outras regiões, de emprego, melhores salários ou diversificação e minimização de risco.

Segundo a abordagem macroeconômica, a migração ocorre devido a diferenças espaciais entre a oferta e demanda por trabalho, gerando diferenciais de salário entre as regiões. Isso faz com que indivíduos que vivem em regiões com oferta de mão de obra abundante e baixos salários migrem para locais com escassez de mão de obra e altos salários. 
As migrações são tratadas com base em teorias de crescimento econômico, nas quais a economia passa por um processo de transição, partindo de uma economia agrícola e estagnada para uma economia industrial e em crescimento. Esse é também um estímulo-chave para a geração de processos migratórios em abordagens histórico-estruturalistas, como será visto adiante. A questão central nesse processo, segundo Ranis e Fei (1961), é a oferta de trabalho (mão de obra). Essa abordagem foi inspirada nos trabalhos de Lewis (1954), que elaborou um modelo econômico de dois setores, posteriormente ampliado por Ranis e Fei, em que a expansão do setor industrial é estimulada pela mobilização do excedente de mão de obra liberado pelo setor agrícola (LEWIS [1954] citado em RANIS e FEI, 1961). Os macroeconomistas enxergam a migração como uma fonte alternativa de trabalho (mão de obra). Ela é mais um fator de produção, assim como o capital, a terra e a mão de obra local.

Por tratarem basicamente dos fluxos agregados de população, há certa dificuldade em apontar o papel da seletividade migratória nessas teorias. Talvez isso decorra do fato de os migrantes serem vistos, nessa abordagem, como indivíduos homogêneos (MASSEY et. al., 1998), o que nos impede de enxergar alguma forma de seleção de determinados indivíduos entre os demais. Devido a isso, seletividade da migração em relação a atributos individuais daria lugar à seletividade espacial, de participação de migrantes de determinadas regiões em detrimento de outras, a parte do sistema de migração.

$\mathrm{Na}$ abordagem microeconômica da migração, 0 foco de análise é 0 indivíduo. A migração é vista como um processo de escolha racional e também como um investimento pessoal, e ocorrerá sempre que os retornos desse investimento forem justificados. Os indivíduos fazem escolhas com base numa avaliação de custo-benefício da migração e migram quando esperam um retorno líquido, normalmente monetário, do deslocamento, ao longo de um determinado período de tempo. A explicação microeconômica para o perfil etário tipicamente jovem da migração é que 0 tempo é relativamente longo entre a migração e a aposentadoria. Para Haris e Todaro (1970), a migração rural-urbana acontece quando há uma expectativa de ganho econômico, que é dado pela diferença salarial entre as regiões de origem e destino. A migração está associada à dinâmica (espacial) do mercado de trabalho, embora, diferentemente das teorias macroeconômicas, o foco agora esteja direcionado para o migrante.

Dentro dessa abordagem, mas com uma análise mais detalhada dos mecanismos pelos quais a seletividade migratória opera, a Teoria do Capital Humano também situa a migração em um contexto de investimento em que os indivíduos decidem migrar ou não com base nos custos e nos retornos da migração. A busca por empregos mais qualificados e com maior remuneração, que muitas vezes leva 
à migração, necessita de um investimento em si próprio para que 0 indivíduo esteja qualificado para a nova ocupação e competitivo no mercado de trabalho (SJAASTAD, 1980; BORJAS, 1996). A mobilidade do trabalho é vista em um modelo de equilíbrio. 0 mercado otimiza a alocação (no espaço) de trabalhadores e firmas, maximizando 0 valor do produto do trabalho. 0 s trabalhadores estão continuamente procurando por melhores empregos (salários), enquanto as firmas buscam os melhores trabalhadores (habilidades). Os indivíduos migram visando uma melhor colocação no mercado de trabalho que, uma vez alcançada, aumentará seu valor à medida que aumenta seu "estoque" de conhecimento, experiência e habilidade (BORJAS, 1996). Por isso, a migração é vista como um investimento em capital humano. As pessoas movem-se para locais onde elas possam ser mais produtivas, de acordo com suas habilidades pessoais.

Um diferencial entre a abordagem do Capital Humano e as outras abordagens microeconômicas é o reconhecimento de que os benefícios da migração ocorrem em um período de tempo limitado, o que faz com que a migração decline com o tempo e, por isso, exiba um padrão etário definido. A seletividade da migração em relação a características pessoais aparece aqui de maneira explícita. 0s migrantes não são selecionados aleatoriamente na população de origem. Variáveis como idade e educação desempenham um papel importante no comportamento migratório (BORJAS, 1996). Isso decorre do fato do ganho líquido com a migração depender do período de tempo em que 0 indivíduo pode usufruir dos benefícios do "investimento migratório". Indivíduos mais jovens têm maior probabilidade de migrar porque o retorno ao investimento será maior a longo prazo. Os que possuem maior qualificação (educação) também são propensos a migrar para locais onde há maior valorização de suas habilidades. Segundo Borjas (1996), os fluxos migratórios apresentam uma composição específica em termos de qualificação dos migrantes, que podem ser mais qualificados (seletividade positiva) ou menos qualificados (seletividade negativa), dependendo dos diferenciais de remuneração da qualificação entre os locais de origem e destino.

A probabilidade migratória declina sistematicamente ao longo da vida produtiva, ou seja, a migração entre os trabalhadores mais velhos é menor do que entre os mais jovens (BORJAS, 1996). Contudo, segundo Sjaastad (1980), quando atingem 0 final do período de atividade e aposentam-se, os indivíduos podem retornar para suas comunidades de origem, migrando mais uma vez.

Além da análise do comportamento individual, as Teorias do Capital Humano destacam a importância do domicílio/família como unidade de decisão da migração. Enquanto há, nos trabalhos em que a unidade de análise é o indivíduo, uma valorização imprescindível das características pessoais dos migrantes e, consequentemente, da seletividade migratória em relação a essas características, isso diminui quando 
se muda a unidade de decisão migratória do indivíduo para a família/domicílio. Para Borjas (1991), se a família for tomada como unidade de decisão, a migração irá acontecer apenas quando 0 ganho econômico agregado da família aumentar com a migração. Busca-se a maximização da renda familiar total, mesmo que a renda individual de um de seus membros seja menor após o deslocamento.

A Nova Economia da Migração do Trabalho, também faz uma valoração econômica da migração, mas apresenta hipóteses diferentes dos modelos apresentados anteriormente. Nessa abordagem, a unidade de decisão migratória é a família/ domicílio. Seus membros tomam decisões coletivas visando não apenas maximizar a renda familiar, mas também buscar estratégias de proteção ao risco, entre as quais inclui-se a migração de algum de seus membros. A migração é, segundo Barbieri (2008), uma das estratégias disponíveis de minimização de risco, condicionadas a fatores como acesso ao crédito e à posse de terra. As famílias tentam controlar os riscos e incertezas (econômicas) via diversificação de atividades produtivas. A migração de seus membros é direcionada para locais onde 0 mercado de trabalho tem fraca correlação com o que vigora no local de origem (MASSEY et. al., 1998).

Além disso, não é apenas a maximização da renda absoluta que está em questão, já que muitas vezes os domicílios comparam sua renda com um grupo de referência. Os indivíduos buscam "improve the household's position (in terms of relative deprivation) with respect to a specific reference group" (STARK e TAYLOR, 1991, p. 1164), o que enfatiza a importância, nessas teorias, da noção de renda relativa.

Como a unidade de análise dessa abordagem é o domicílio, a seletividade da migração fica condicionada às características domiciliares e não às individuais. Contudo, segundo Stark e Bloom (1985), pode haver dentro de cada domicílio uma seletividade com relação às habilidades individuais e ao poder de barganha de cada membro da família. Isso reforça, por exemplo, o papel das estruturas de gênero nas decisões familiares de migração.

\section{Estruturas sociais e migração}

Nessa seção, serão descritas as principais ideias das abordagens que não fazem uma valoração puramente econômica dos determinantes das migrações. Elas expandem a noção do migrante como indivíduo racional que age respondendo não só à diferença salarial entre duas regiões, mas que também é influenciado por aspectos sociais e culturais. 
Segundo De Jong e Gardner (1981), a expectativa de atingir certos objetivos constitui a motivação principal para a migração. Essa ocorre devido ao desejo de indivíduos e famílias manterem ou elevarem sua qualidade de vida. Esses autores desenvolveram um modelo de comportamento migratório de valoração de expectativas, em que Figuram questões como riqueza, status, conforto, autonomia, parentesco e afiliação. A seletividade migratória aparece quando os autores apontam para os grupos de indivíduos mais suscetíveis a cada um desses estímulos. Os grupos de potenciais migrantes diferenciam-se devido a características individuais e familiares. Entre as primeiras destacam-se a idade, 0 sexo, a condição de atividade e 0 nível de renda. Com relação às características familiares, diferenciam-se segundo as etapas do ciclo de vida familiar. Assim, entre os potenciais migrantes, os jovens preocupamse principalmente com melhores salários, enquanto as famílias com crianças em idade escolar preocupam-se com a estrutura de serviços das localidades, e os idosos preocupam-se em viver próximos da família e dos amigos (DE JONG e GARDNER, 1981, p. 53). Há certa interação entre os níveis de tomada de decisão individual e familiar, sendo que a seletividade migratória expressa-se em ambos os níveis.

A intenção de migrar para manter ou elevar a qualidade de vida das pessoas está presente na Teoria das Respostas Multifásicas, apresentada por Davis em 1963. Segundo 0 autor, juntamente com estratégias como 0 adiamento do casamento, 0 celibato, 0 aborto e a contracepção, a migração ocorre em resposta a estímulos sociais e econômicos que levam os indivíduos, baseados na percepção do nível de qualidade de vida, à tentativa de aproveitarem as vantagens decorrentes de oportunidades surgidas com a modernização. Essas respostas são consideradas "multifásicas" à medida que os domicílios podem adotá-las simultaneamente.

Nas abordagens histórico-estruturalistas, em lugar de decisões racionais e das estratégias de comportamento individual e familiar, as migrações são condicionadas por processos socioeconômicos e refletem a dinâmica estrutural e espacial desses determinantes (macro) sociais. Dentro dessa abordagem, há uma corrente de cunho marxista que se baseia no fato de que as migrações ocorrem devido às modificações introduzidas na sociedade agrária pela industrialização e, em última instância, pelo modo capitalista de produção. (GAUDEMAR, 1977). É uma análise que tende a interpretar a migração como um projeto coletivo atrelado à organização do capital e do mercado global de trabalho. Ao contrário da liberdade de movimento (individualismo), os atores estão sujeitos às pressões econômicas do sistema social contemporâneo.

Singer (1980), por exemplo, trata as migrações como um processo social em que a unidade atuante não é 0 indivíduo, mas 0 grupo social em que este se insere. Ele apenas cita que a seletividade migratória pode ocorrer em algum momento. 


\begin{abstract}
Embora o grupo social seja levado, por certas causas estruturais, a migrar, é lógico que nem todos os seus membros o façam de imediato. (...) Há, neste sentido, uma certa seletividade dos fatores de expulsão (...) que pode ser assimilada a uma diversidade de motivos individuais que leva alguns a migrar e a outros não (SINGER, 1980, p. 237).
\end{abstract}

Contudo, a seletividade que transparece nessa corrente é a seletividade de regiões, determinada pela maneira que elas estão inseridas na dinâmica econômica global. Segundo Barbieri (2005, p. 30) as regiões "should be regarded as being highly sensitive to structural changes engendering labor and capital arrangements in the national and international economies." As características individuais interagem e subordinam-se a fatores agregados, ligados à estrutura do mercado de trabalho nacional e internacional.

Uma outra vertente destaca o papel das redes sociais nas migrações. Em termos gerais, a rede social reflete a gama de relações pessoais que a pessoa mantém (LITWIN, 1995). Tratando especificamente das redes sociais e da migração, podemos defini-las como conjuntos de laços interpessoais que ligam potenciais migrantes com migrantes de fato e não migrantes nas áreas de origem e destino, via relações de parentesco, amizade e naturalidade (MASSEY, 1990). Os contatos dos migrantes no local de destino desempenham um papel fundamental da propensão migratória, tanto no nível individual quanto domiciliar. As redes sociais proveem informações que reduzem o risco da migração. São uma espécie de capital "intangível" (capital social) que os indivíduos/domicílios possuem (TAYLOR, 1986) e que reduzem os riscos da migração.

A ocorrência da migração é atribuída principalmente à busca por trabalho. Dessa maneira, a seletividade pode expressar-se à medida que os retornos do trabalho (salários) são influenciados por características individuais como sexo, idade, educação, habilidades e experiência migratória (TAYLOR, 1986, p. 155). Contudo, embora os migrantes tomem decisões baseados em suas características pessoais, a ocorrência da migração está fortemente relacionada com a existência e eficiência das redes sociais a que 0 indivíduo pertence (MASSEY, 1990).

Sendo assim, é o "capital social" que aparece como elemento de diferenciação e seletividade. Os indivíduos pertencentes a determinada rede social são mais propensos à migração, caso essa rede social favoreça o deslocamento, do que indivíduos externos a ela, ou seja, o capital social do indivíduo influencia a sua propensão migratória.

Garip (2008) vai além na relação entre seletividade e capital social, afirmando que o efeito do capital social do migrante não é uniforme e atua de maneira diferente em cada contexto. Segundo o autor, existem diferentes mecanismos pelos quais 0 
capital social opera e as características individuais dos potenciais migrantes são atributos preditores do seu comportamento migratório. Um exemplo é o fato do indivíduo já ter migrado alguma vez, o que aumenta sua probabilidade de migrar novamente dado que sua experiência anterior reduz os custos e riscos da migração. Garip (2008) afirma que essa questão desafia 0 estado de conhecimento atual, ao questionar 0 fato do capital social não afetar a todos indivíduos de maneira linear. Barbieri (2005), ao afirmar que quanto mais estabelecida a rede migratória maiores são os fluxos e menor a seletividade de seus membros, também corrobora a ideia de que há uma ligação importante entre redes sociais e seletividade. 


\section{Considerações finais}

0 presente trabalho fez uma revisão bibliográfica das principais correntes teóricas que explicam o fenômeno migratório, buscando apontar como a seletividade da migração em relação a atributos individuais é destacada em cada uma dessas abordagens, e em quais delas ela é omitida. Devido à compartimentalização disciplinar, à fragmentação teórica e à consequente variação da escala de análise de cada abordagem apresentada, transparece o fato de que as correntes que concentram sua análise nos indivíduos destacam explicitamente a seletividade da migração, enquanto as abordagens que analisam as migrações em uma escala maior dão menor peso a características individuais em detrimento dos atributos das regiões de origem e destino dos migrantes na seleção de migrantes.

É certo que, quanto menor o nível de análise, mais destacadas serão as características individuais e maior será a relevância dada ao papel da seletividade migratória. Contudo, se compartilharmos da opinião de que a decisão migratória ocorre em um ambiente em que múltiplos níveis operam simultaneamente, podemos concluir que, qualquer que seja o motivo real que culminou em migração, ele foi permeado por características individuais que levaram alguns indivíduos a migrar, enquanto outros permaneceram. Sempre que o debate situa-se em torno da questão de "quem se move", a questão da seletividade torna-se central.

A abordagem microeconômica destaca o papel da seletividade, principalmente em relação à idade e à educação, embora não considere a heterogeneidade entre os indivíduos em termos de níveis de habilidade e atitude. A seletividade permeia os pressupostos da Teoria do Capital Humano e, dentro do processo de barganha intradomiciliar, da Nova Economia da Migração do Trabalho. Já as abordagens contextuais e estruturais enfatizam a importância dos processos agregados e as diferenças espaciais na distribuição dos fatores de produção como terra, trabalho e recursos naturais, não levantando aspectos individuais.

A seletividade é abordada de outra forma nas teorias macro, como por exemplo, na forma como a distribuição espacial dos fatores de produção influencia diferentes indivíduos a migrar.

Com base na discussão apresentada vê-se que a seletividade é uma característica fundamental do fenômeno migratório, independente da escala de análise e da abordagem conceitual utilizada. 


\section{Referências}

BARBIERI, A. F. People, land and context: multi-scale dimensions of population mobility in the Ecuadorian Amazon. 2005. $204 \mathrm{f}$. Tese (Doutorado) - University of North Carolina at Chapel Hill, 2005.

BARBIERI, A. F. Mobilidade populacional, meio ambiente e uso da terra em áreas de fronteira: uma abordagem multiescalar. Revista Brasileira de Estudos Populacionais, Campinas, v. 24, n. 2, p. 225-246, jul./dez. 2007.

BILSBORROW, R. E. Sample Design. In: BILSBORROW, R. E.; OBERAI, A. S.; STANDING, G. Migration survey in low income countries: guidelines for survey and questionnaire design. London; Sidney: Croom Helm, 1984.

BORJAS, G. J. Labor Economics. New York: Mac Graw Hill, 1996.

BORJAS, G. J.; BRONARS, S. G. Immigration and the family. Journal of Labor Economics, Chicago, v. 9, n. 2, p. 123-148, Apr. 1991.

BURES, R. Migration and the life course: Is there a retirement transition? International Journal of Population Geography, Chichester, v. 3, n. 2, p. 109-119, Sep. 1997.

DAVIS, K. The theory of change and response in modern demographic history. Population index, Princeton, v. 29, n. 4, p. 345-366, 0ct. 1963.

DE JONG, G.F.; GARDNER, R.W (Eds.). Migration decision making: multidisciplinary approaches to microlevel studies in developed and developing countries. New York: Pergamon Press, 1981.

GARIP, F. Social capital and migration: how do similiar resourses lead to divergent outcomes? Demography, Seattle v. 45, n. 3, p. 591-617, Aug. 2008.

GAUDEMAR, J. P. Mobilidade do trabalho e acumulação do capital. São Paulo: Editorial Estampa, 1977.

GOLGHER, A. B. Os determinantes da migração e diferenciais entre migrantes e não-migrantes em Minas Gerais. 2001. 187 f. Tese (Doutorado) - Centro de Desenvolvimento e Planejamento Regional, Universidade Federal de Minas Gerais, Belo Horizonte 2001.

HARRIS, J. H.; TODARO, M. P. Migração, desemprego e desenvolvimento: uma análise com dois setores. In: MOURA, H. A. (Org.). Migração interna, textos selecionados: teorias e métodos de análise. Fortaleza: BNB, 1980.

HEATON, T. B.; CLIFFORD, W. B.; FUGUITT, G. V. Temporal shifts in the determinants of young and elderly migration in nonmetropolitan areas. Social Forces, Chapel Hill, v. 60, n.1, p. 41-60, Sep. 1981.

KALLAN, J. E. A multilevel analysis of elderly migration. Social Science Quarterly, Austin, Tex., v. 74, n. 2, p. 403-416, Jun. 1993. 
LEE, E. S. A Theory of Migration. Demography, Seattle, v. 3, n. 1, p. 47-57, Jan. 1966.

LITWIN, H. The Social Network of Elderly Immigrants: an analytic typology. Journal of Aging Studies, New York, v. 9, n. 2, p. 155-174, Summer. 1995.

MARQUES, D.; RODRIGUES, L. Emigrantes e imigrantes de Belo Horizonte em relação ao restante da RMBH: uma aplicação do método "Grade of Membership" (GoM). In: ENCONTRO NACIONAL DE ESTUDOS POPULACIONAIS, 15., 2006. Caxambu. Desafios e oportunidades do crescimento zero: anais. [Campinas]: ABEP, 2006.

MASON, K. 0. Gender and demographic change: what do we know? Liege, Belgique: International Union for the Scientific Study of Population, 1995.

MASSEY, D. Social structure, household strategies and the cumulative causation of migration. Population Index, Princeton, v. 56, n. 1, p. 3-26, Spring. 1990.

MASSEY, D. et al. Worlds in motion: understanding international migration at the end of the millennium. Oxford: Clarendon Press, 1998.

PRESTON, S. H.; HEUVELINE, P.; GUILLOT, M. Demography: measuring and modeling population processes. Oxford: Blackwell Publishers, 2001.

RADCLIFFE, S. A. Mountains, maidens and migration: gender and mobility in Peru. In: CHANT, S. Gender and migration in developing countries. London: Belhaven Press, 1992.

RANIS, G.; FEl J,H,C. A theory of economic development. American Economic Review N. 51. 1961. p. 533-65.

RAVENSTEIN, E. G.. The laws of migration. Journal of the Royal Statistical Society. Series A (Statistics in Society), London, v. 52, n. 2, p. 241-305, Jun. 1889.

RILEY, N.; GARDNER, R. W. Migration decisions: the role of gender. In: UNITED NATIONS. Internal migration of women in developing countries. New York, 1993.

ROGERS, A.; CASTRO, L. Model migration schedules. Luxemburg: IASA, 1981. (Research Report, 81-30).

SINGER, P. Migrações internas: considerações teóricas sobre o seu estudo. In: MOURA, H. A. (Org.). Migração interna, textos selecionados: teorias e métodos de análise. Fortaleza: BNB, 1980.

SJAASTAD, L. A. Os custos e os retornos da migração. In: MOURA, H. A. (Org.). Migração interna, textos selecionados: teorias e métodos de análise. Fortaleza: BNB, 1980.

STARK, 0.; BLO0M, D. The new economics of labor migration. AEA Papers and Proceedings: frontiers in demographic economics, Pittsburgh, v. 75, n. 2, p. 173178 May. 1985. 
STARK, 0.; TAYLOR, E. Migration incentives, migration types: the role of relative deprivation. The Economic Journal, St. Andrews, v. 101, n. 408, p. 1163-1178, Sep. 1991.

TAYLOR, J. E. Differential migration, networks, information an risks. In: STARK, 0. Migration, human capital and development. Greenwich: Connecticut, Jai Press, 1986. p. 147-171. 
